\title{
NUMERICAL SIMULATION OF HEAT TREATMENT PROCESS OF ALUMINIUM PROFILES
}

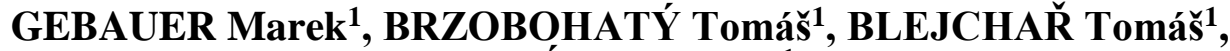 \\ KARÁSEK Tomášs ${ }^{1}$
}

\begin{abstract}
${ }^{1}$ IT4Innovations, VSB - Technical University of Ostrava,17. listopadu 15/2172, 70800 Ostrava, Czech Republic, e-mail: marek.gebauer@vsb.cz,tomas.brzobohaty@vsb.cz,tomas.blejchar@vsb.cz,tomas.karasek@vsb.cz
\end{abstract}

\begin{abstract}
The paper deals with the simulation of cooling processes of the aluminium profiles inside the water quench. Cooling of profile surfaces is performed by water spray, which is created by mixing a water and an air in a nozzles. Formulas were found in literature, modified and applied to a given problem that significantly simplified a solution. The task of numerical simulations was to determine temperature and velocity profile on aluminium profile surfaces for establishing of the heat transfer coefficient which was used as the convective boundary condition necessary to solve the heat transfer in the aluminium profile by finite element method. The difference between FEM and CFD results is up to $10 \%$.
\end{abstract}

KEYWORDS: Multiphase flow, heat transfer, CFD, water quenching, aluminium

\section{Introduction}

Aluminium profile leaves the die at a temperature of approximately $500-550^{\circ} \mathrm{C}$ during production. It is needed to be cooled at desired temperature in the range of $200-250^{\circ} \mathrm{C}$ in a relatively short time 15-30 seconds. Intensive cooling is achieved by using nozzles arranged in modules in the water quench. This paper deals with a specific water quench (WQ), which is equipped by thirty nozzle modules (see Figure 1 for reference). Side walls of WQ are fitted by seven nozzle modules arranged side by side. The top and bottom wall of WQ have eight nozzle modules, of which first and last are inclined towards to the centre of the WQ. The cooled aluminium profile is transported to the WQ by rollers at a certain speed, which depends on the type of a profile and its requested output temperature. Unused water is drained through the floor channels back into the reservoir after the WQ walls have been wetted. Water vapour and an air are vacuumed by WQ ceiling ventilation. The cooling process takes place automatically after setting the correct water mass flow and air pressure in the nozzle modules.

Cooling of profile surfaces is performed by water spray, which is created by mixing water and an air in nozzles [11]. The total number of nozzles actively involved in this mixing process depends on the operational conditions of the WQ and could be around one thousand of nozzles. Setting of the operational conditions i.e. amount of the water is based on the experience of the Water Quench operator. For each new profile where prior experience is missing a high rejection rate of resulting product as a consequence of the unrepeatable setting and trial-and-error process occurs.

The task of numerical simulations was to determine temperature and velocity field on profile surfaces for establishing of the heat transfer coefficient (HTC) which was used as the convective boundary condition necessary to solve the heat transfer in the aluminium profile by finite element method. This procedure allows us to reduce whole problem from approximately 800 millions of unknowns to thousands of unknowns which are solvable on any PC workstation. To be able to solve full computational fluid dynamics (CFD) simulation a precisely defined geometry of nozzles, modelling of inhomogeneous multiphase flow, heat 
transfer solutions in aluminium profile including air inside the full profile have to be considered. In contrast, simple heat transfer simulation was performed in simplified model.

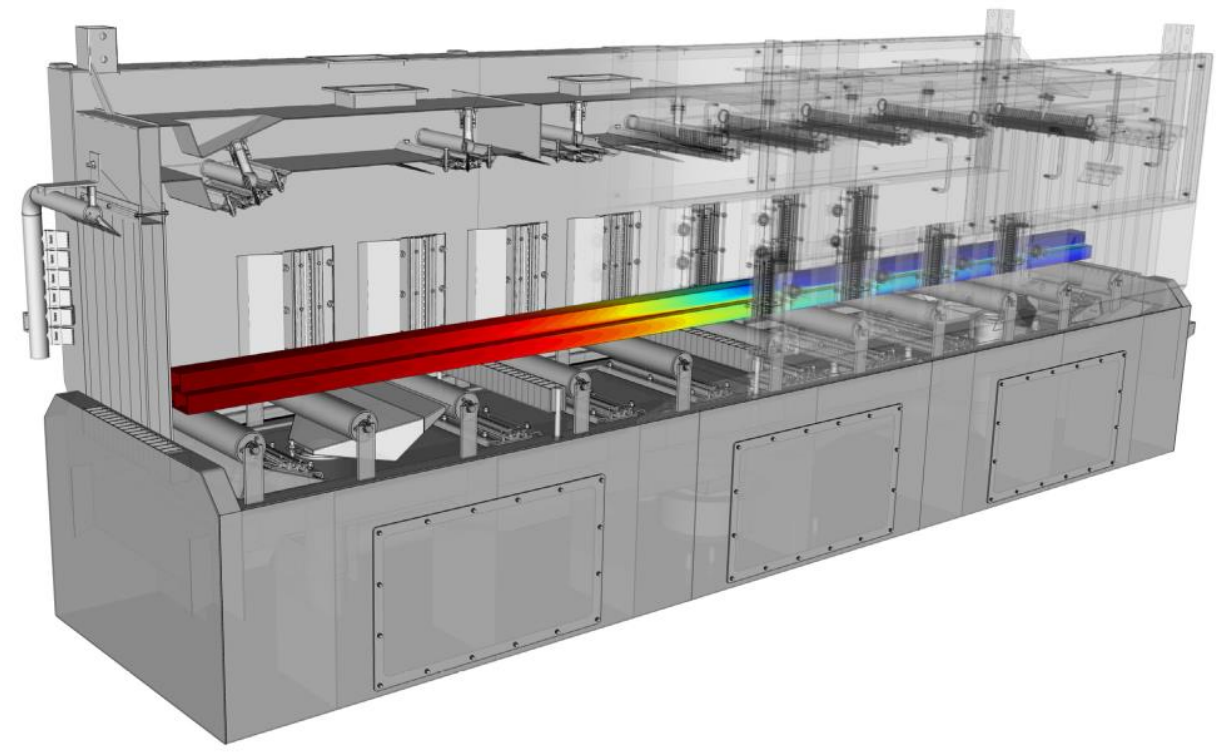

Fig. 1 Water quench

\section{CFD simulation}

The temperature distribution, velocity profile and water volume fraction results were calculated on the walls of the examined profile at the shape of a square with dimensions of $80 \mathrm{~mm} \times 80 \mathrm{~mm}-8 \mathrm{~mm}$. The cooling of the profile was done only by the top and bottom modules of a nozzle in reality, according to this fact CFD analysis had to be set.

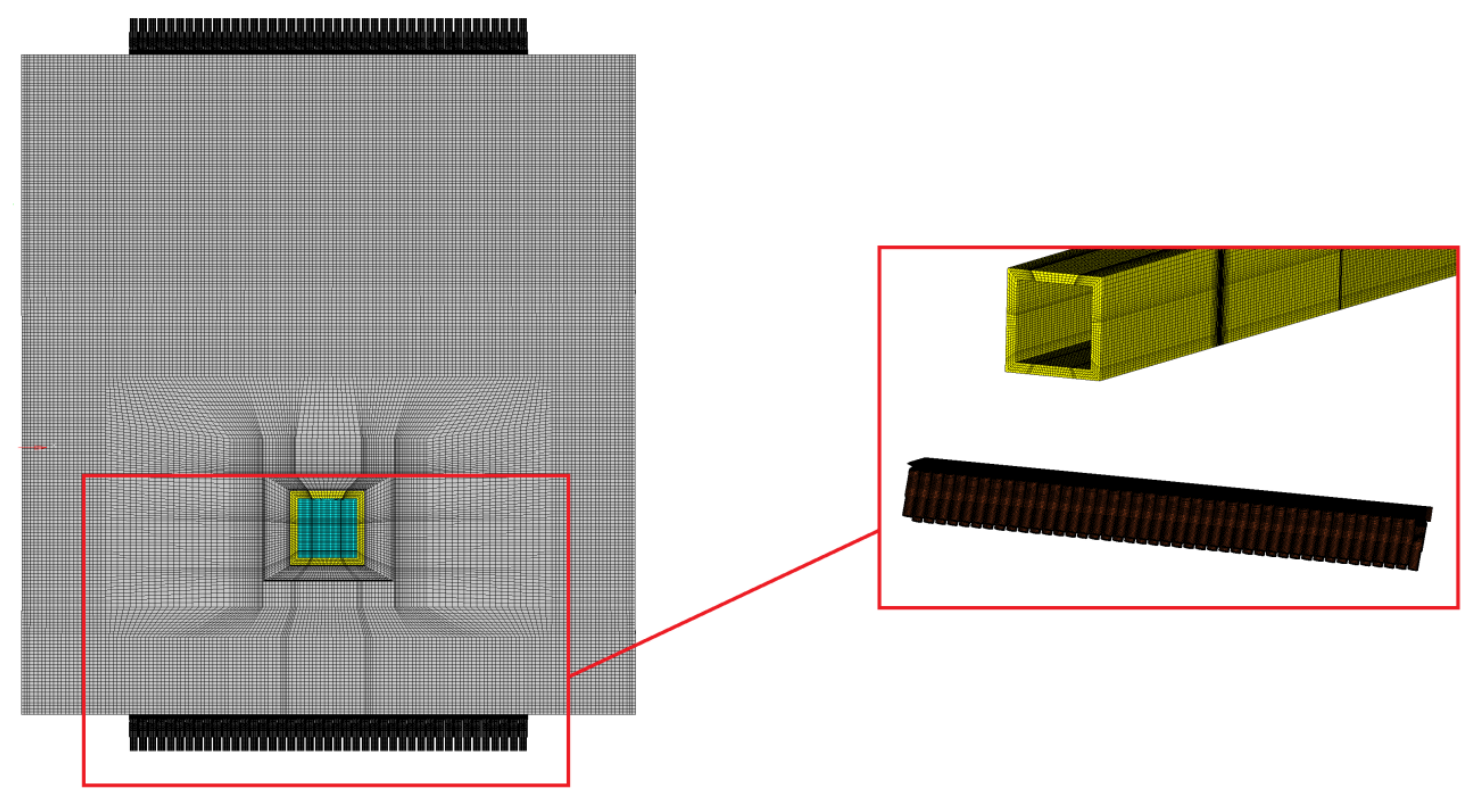

Fig. 280 million hex mesh

CFD analysis contained about 80 million cells, Fig 2. The pure hexahedral mesh was created in Hypermesh 13.0 software. It was divided into a total of nineteen domains (nozzle 
modules, profile, water quench space and space inside the profile).The domains were interconnected by GGI or 1:1 interpolation functions depending on the mesh created between domains. The empty space inside at the profile was defined by a water-free domain. The inhomogeneous flow inside the water quench was assumed. The radiation term was not implemented yet $[1,2]$. The water mass flow rate was determined by individual zones containing a given number of nozzle modules, Fig 3. Other parameters are defined in Tab. 1. The physical parameters of the aluminium profile are shown in the Tab $2[4,5,10]$. Transient analysis, which took approximately 3 days, was performed for initialization. Followed by one day steady-state simulations. Salomon supercomputer operated by IT4Innovations national supercomputing centre was used to run the simulations.

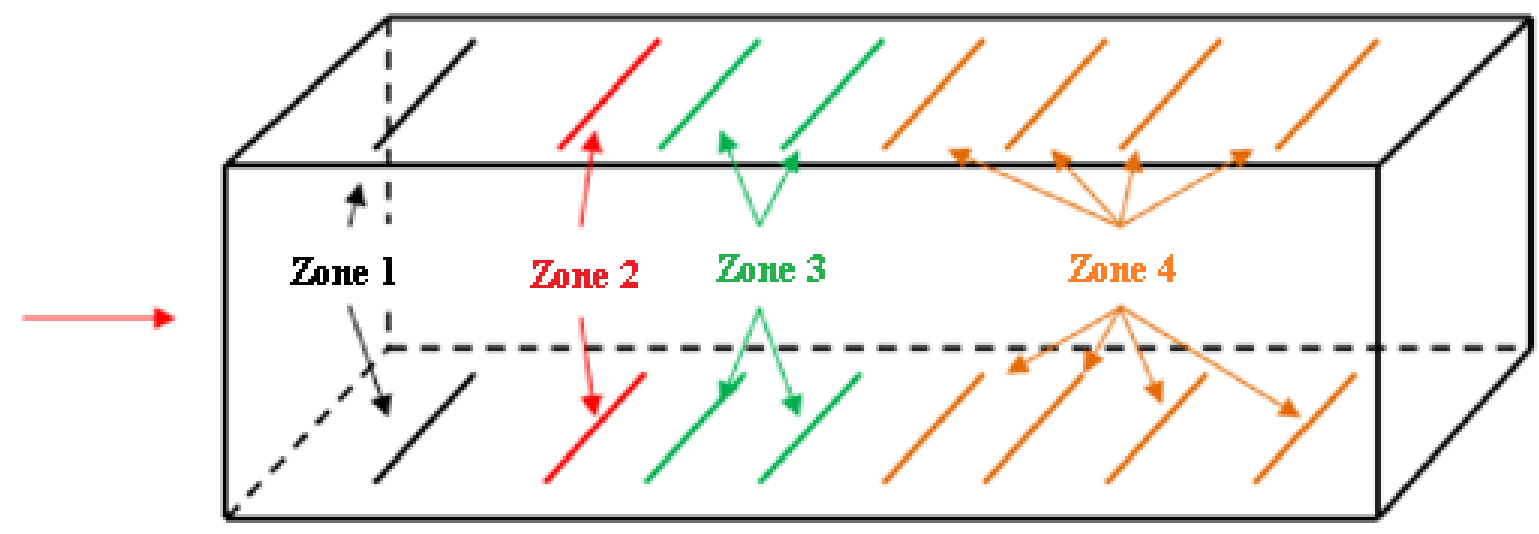

Fig. 3 Schematic illustration of a water mass flow

Tab. 1 Input parameters for CFD simulation

\begin{tabular}{|l|c|c|c|}
\hline \multicolumn{2}{|c|}{ Input parameters } & \multicolumn{2}{c|}{ Water mass flow $[\mathrm{kg} / \mathrm{s}]$} \\
\hline Initial profile temperature $\left[{ }^{\circ} \mathrm{C}\right]$ & 528 & Zone 1 - 2 nozzles & 1.14 \\
\hline Profile movement velocity $[\mathrm{m} / \mathrm{min}]$ & 4.17 & Zone 2 - 2 nozzles & 1.14 \\
\hline Input air pressure $[\mathrm{bar}]$ & 0.101 & Zone 3 - 4 nozzles & 1.968 \\
\hline Input water and air temperature $\left[{ }^{\circ} \mathrm{C}\right]$ & 20 & Zone 4 - 8 nozzles & 4.48 \\
\hline Turbulent model & $k-\omega S S T$ & & \\
\hline Turbulent intensity $[\%]$ & 5 & & \\
\hline
\end{tabular}

Tab. 2 Used parameters of the aluminium profile

\begin{tabular}{|l|c|}
\hline \multicolumn{2}{|c|}{ Aluminium parameters } \\
\hline Specific heat capacity $[\mathrm{J} / \mathrm{kgK}]$ & $0.5267 \cdot \mathrm{T}+775.13$ \\
\hline Density $\left[\mathrm{kg} / \mathrm{m}^{3}\right]$ & 2702 \\
\hline Thermal conductivity $[\mathrm{W} / \mathrm{mK}]$ & $0.1542 \cdot \mathrm{T}+118.71$ \\
\hline
\end{tabular}

The temperature and velocity field results are shown in Fig. 4. The result shows the profile was cooled to the lowest temperature of about $157^{\circ} \mathrm{C}$. The average temperature in the profile at exit wall was $175^{\circ} \mathrm{C}$.

Figure 5 shows a velocity profile near the wall. Velocity profile is drawn along a red line shown in Figure 6. The distance of the red line from the wall is approximately $30 \mathrm{~cm}$.

The heat transfer coefficient results are shown in Fig. 7. It is obvious that the highest heat transfer at the wall of aluminium profile occurs in front of noozles. 


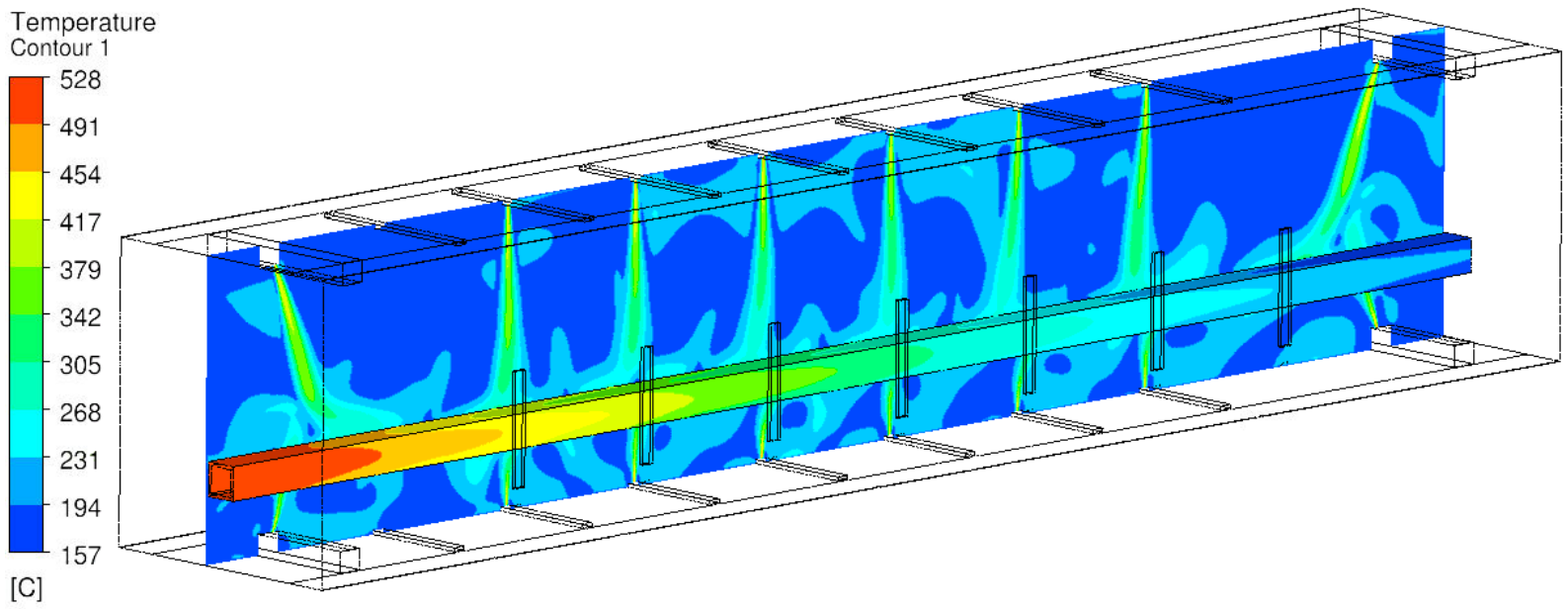

Fig. 4 Temperature distribution and velocity profile inside of water quench

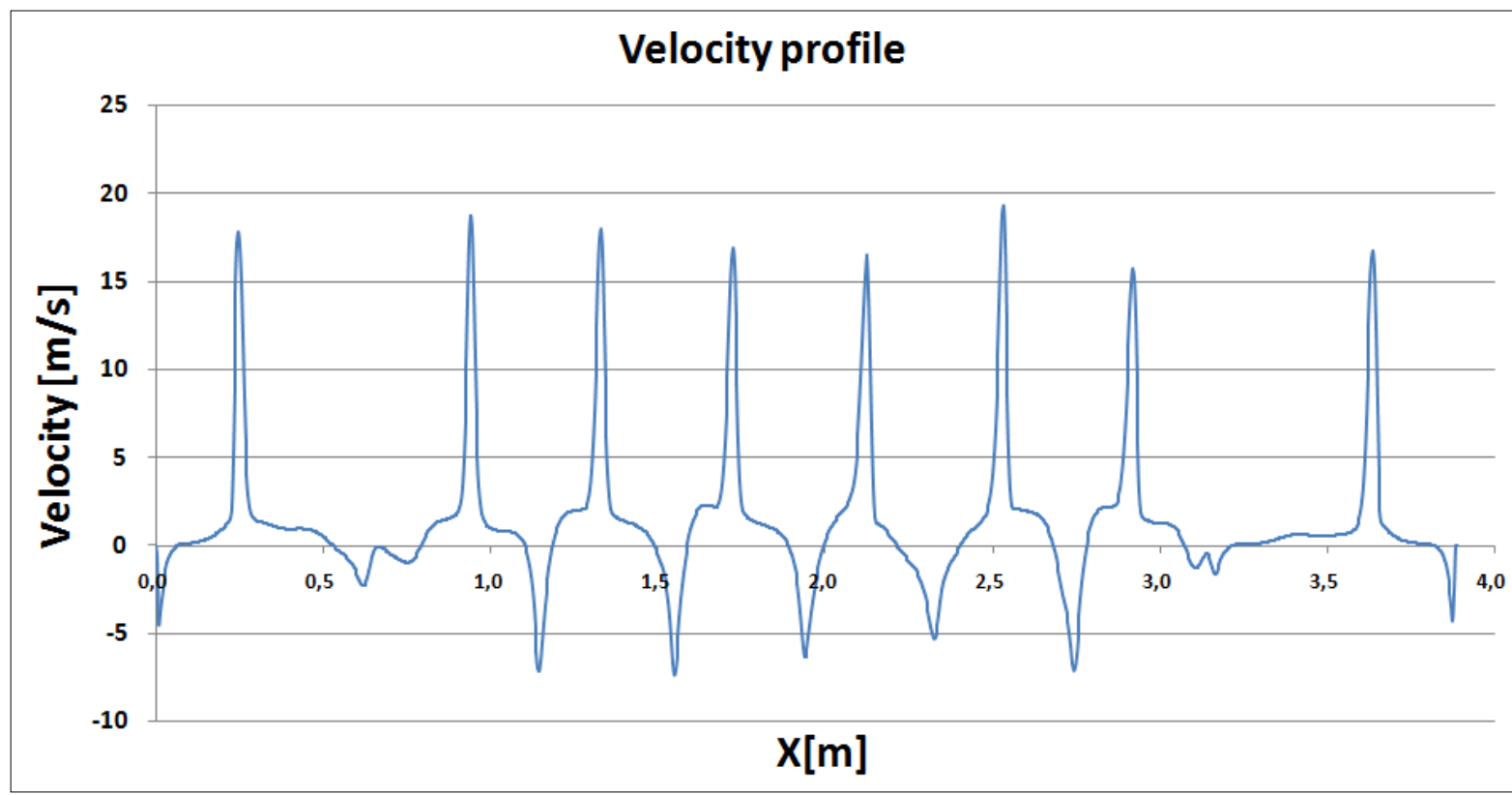

Fig. 5 Velocity flow close to the aluminium profile

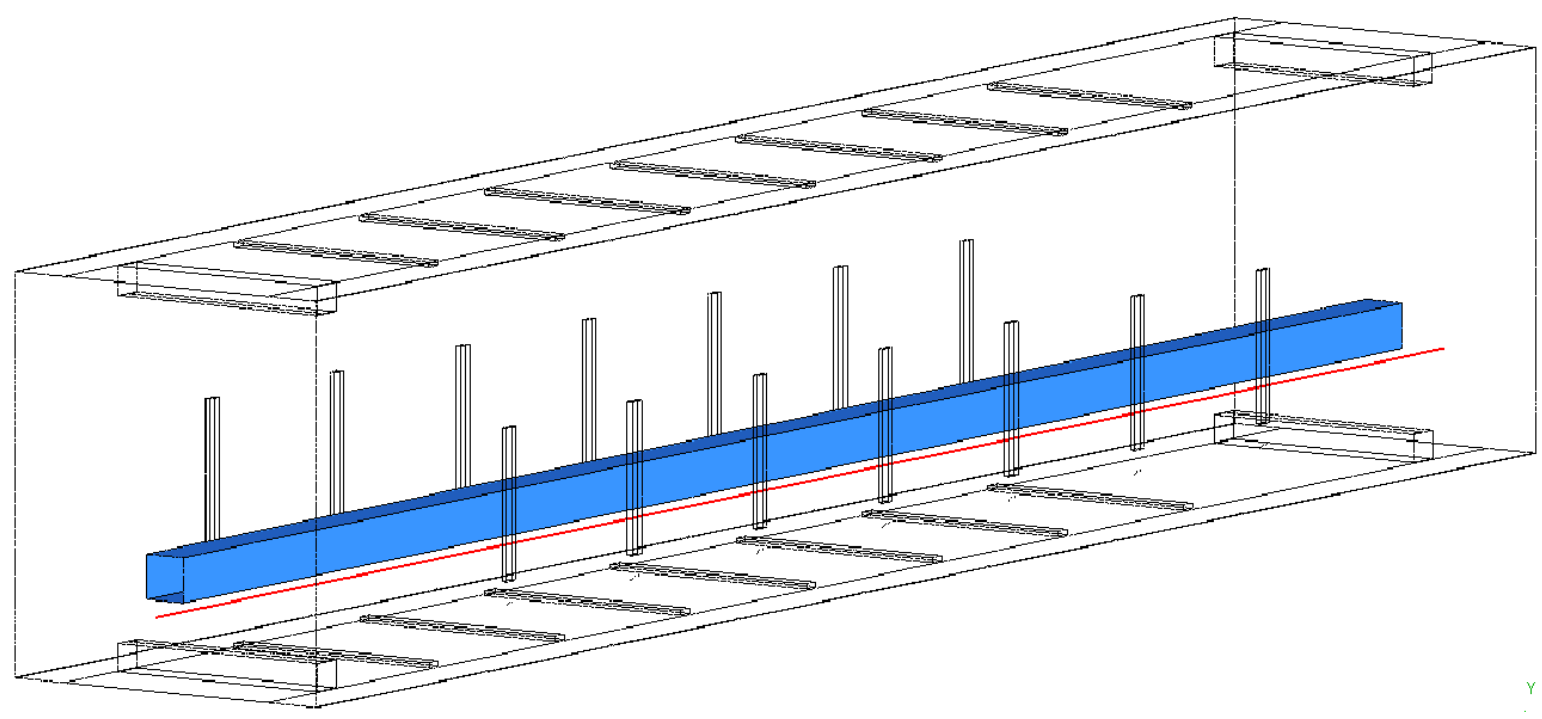

Fig. 6 Location of a red line 


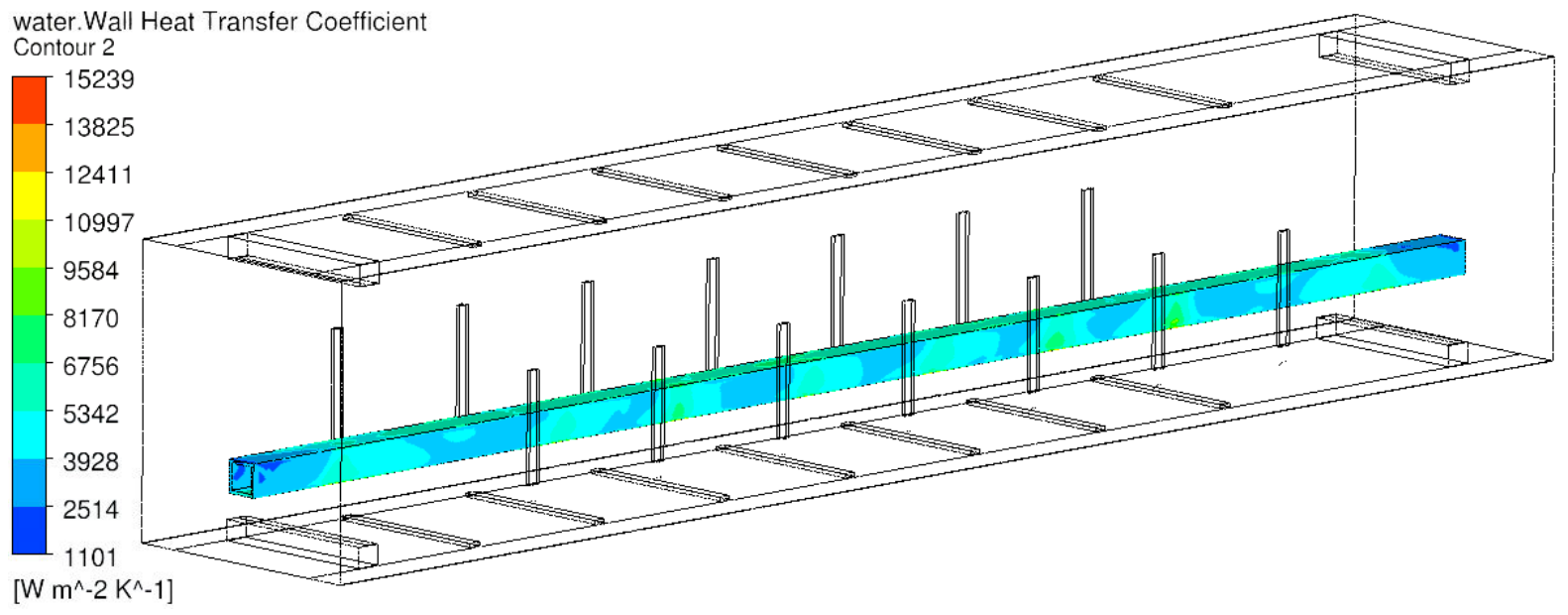

Fig. 7 Distribution of heat transfer coefficient

The volume fraction of water in the air is shown in Figure 8. The highest concentration of water is located in the middle and bottom of WQ.

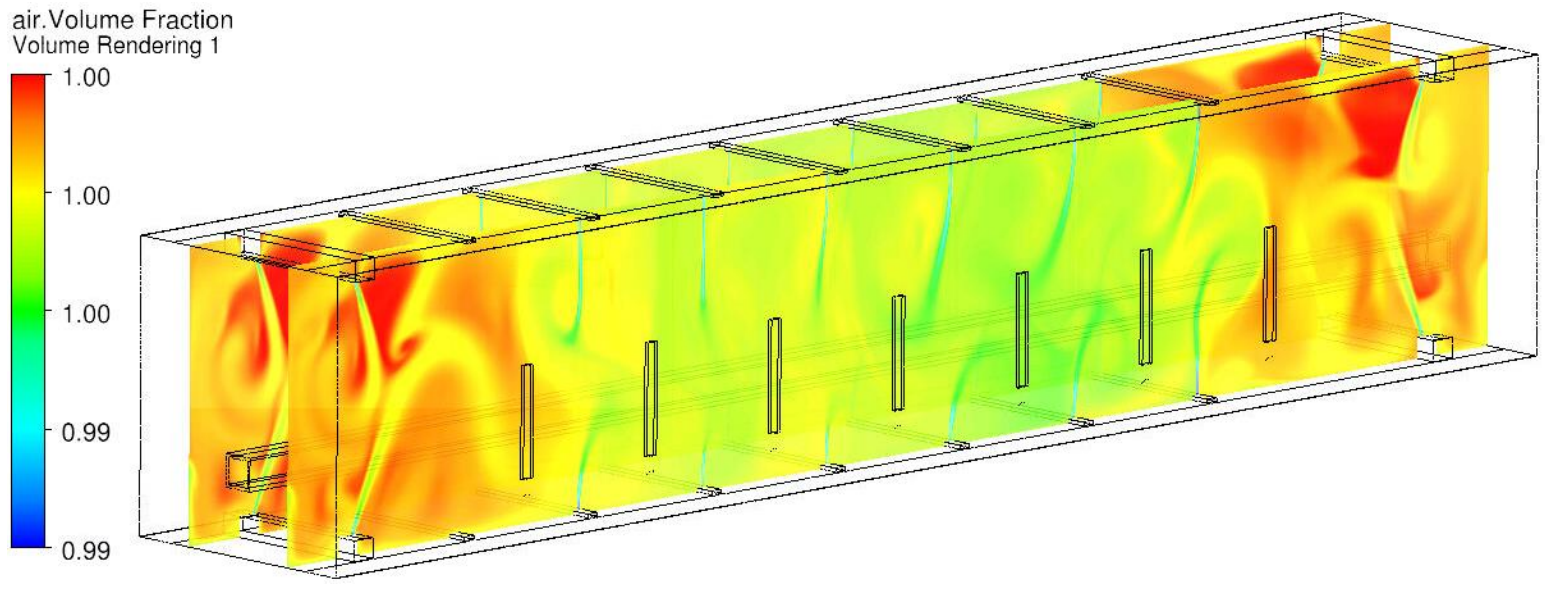

Fig. 8 Volume fraction inside of water quench

\section{FEM simulation}

It was necessary to develop a solution enabling the evaluation of individual criteria in real time. For the automated calculation purposes as a support in decision making and control of the cooling process. We have developed a solution based on the finite element method for these requirements. This method combines advection-diffusion equation with nonlinear boundary conditions for heat transfer in aluminium profile in motion.

Phase change (water - vapour) is assumed to the near hot profile walls. This physical behaviour defined a two temperature intervals for which the final convective formulas were found. By comparing the results from CFD simulations with experimental data, a formula (1) was used to calculate HTC on the surface of the profile above $100^{\circ} \mathrm{C}$ and the formula (2) for calculating HTC on the surface of the profile below $100^{\circ} \mathrm{C}$. Both formulas were implemented in the FEM ESPRESO software solver.

$$
\begin{aligned}
& H T C_{\text {tot }(>100)}=v_{f l} H T C_{\text {steam }}+\left(1-v_{f l}\right) \cdot H T C_{\text {air }}+5, \\
& H T C_{\text {tot }(<100)}=v_{f l} H T C_{\text {water }}+\left(1-v_{f l}\right) \cdot H T C_{\text {air }}+5,
\end{aligned}
$$


where $v_{f l}$ is water volume fraction of profile at surface (received from CFD simulation); $H T C_{\text {steam }}$ is HTC defined at formula (3); HTC air, water is the minimum HTC value calculated by empirical formulas given by formula (4) and (5). First one is defined for flowing perpendicular to the long thin plate, next one for flowing parallel to the long thin plate $[6,7]$.

$$
H T C_{\text {steam }}=C \cdot 0.425 \cdot\left[\frac{\lambda_{v}{ }^{3} \cdot \rho_{v} \cdot g \cdot\left(\rho_{l}-\rho_{v}\right) \cdot\left(L+0.4 \cdot c_{p v} \cdot\left(T_{w}-T_{s a t}\right)\right)}{\eta_{v} \cdot\left(T_{w}-T_{s a t}\right) \cdot \sqrt{\frac{\sigma}{g \cdot\left(\rho_{l}-\rho_{v}\right)}}}\right]^{\frac{1}{4}},
$$

where $C$ is constant determined from experimental data; $g$ is gravity constant; $\eta_{v}$ is water steam dynamic viscosity (depends on the temperature); $T_{\text {sat }}$ is saturation temperature (water boiling temperature at atmospheric pressure); $T_{w}$ is wall temperature; $C_{p v}$ is water steam specific heat capacity (depends on the temperature); $L$ is water vaporization heat; $\rho_{l}$ is liquid water density at $100^{\circ} \mathrm{C} ; \rho_{v}$ is water steam density defined by state equation; $\lambda_{v}$ is water steam thermal conductivity depends on the temperature and $\sigma$ is water surface tension. Where $\lambda_{a, w}$ is thermal conductivity of air and water mixture defined by (6); $L_{p e r}$ is wall width; $L_{p a r}$ is wall length; $P r$ is Prandtl's number defined by (7) a $R e$ is Reynold's number defined by (8) [3].

$$
\begin{gathered}
\operatorname{HTC}_{(\text {air,water }) \text { per }}=\frac{\lambda_{a, w}}{L_{\text {per }}} 0,228 \operatorname{Pr}^{1 / 3} \operatorname{Re}^{0,731}, \\
H T C_{(\text {air }, \text { water }) \text { par }}=2 \cdot \frac{\lambda_{a, w}}{L_{\text {par }}} \cdot \frac{0.3387 \cdot \operatorname{Pr}^{1 / 3} \operatorname{Re}^{1 / 2}}{\left(1+\left(0.0468 / \operatorname{Pr}^{\frac{2}{3}}\right)\right)^{1 / 4}} \\
\lambda_{(a, w)}=\lambda_{(w)} \cdot v f_{(w)}+\lambda_{(a)} \cdot\left(1-v f_{(w)}\right),
\end{gathered}
$$

where $v f_{(w)}$ is water volume fraction.

$$
\begin{gathered}
P r=\frac{C_{p(a, w)} \eta_{(a, w)}}{\lambda_{(a, w)}}, \\
R e=\frac{v_{a} d}{\mu_{(a, w)}},
\end{gathered}
$$

where $C_{p}$ is specific heat capacity of water and air mixture defined by (9); $\eta$ is dynamic viscosity of water and air mixture defined by $(10) ; \mu_{(a, w)}$ is kinematic viscosity of water and air mixture defined by (11), $v_{a}$ is the mean value of a fluid velocity as a function of a distance from the nozzle orifice and a radius defined by (12) and $d$ is hydraulic diameter.

$$
\begin{gathered}
C_{p_{(a, w)}}=C_{p_{(w)}} \cdot v f_{(w)}+C_{p_{(a)}} \cdot\left(1-v f_{(w)}\right), \\
\eta_{(a, w)}=\eta_{(w)} \cdot v f_{(w)}+\eta_{(a)} \cdot\left(1-v f_{(w)}\right), \\
\mu_{(a, w)}=\mu_{(w)} \cdot v f_{(w)}+\mu_{(a)} \cdot\left(1-v f_{(w)}\right), \\
v_{a(x, r)}=7,75 \cdot \frac{\sqrt{\frac{\rho_{n} \cdot Q_{v}^{2}}{\left.\rho_{(x)}\right)^{2}}}}{x} \cdot e^{\left(\frac{-r^{2}}{0,103^{2} \cdot x^{2}}\right)}
\end{gathered}
$$

where $\rho_{n}$ is density of water and air mixture at outlet of nozzles; $Q_{v}$ is volume flow of nozzle; $\rho_{(x)}$ is density of water and air mixture at actual distance; $S$ is cross section of nozzle; $x$ is distance; $r$ is radius of nozzle. Figure 9 shows schematic velocity profile calculated by (12) applied on surfaces of profile in the FEM analysis $[8,9]$ 


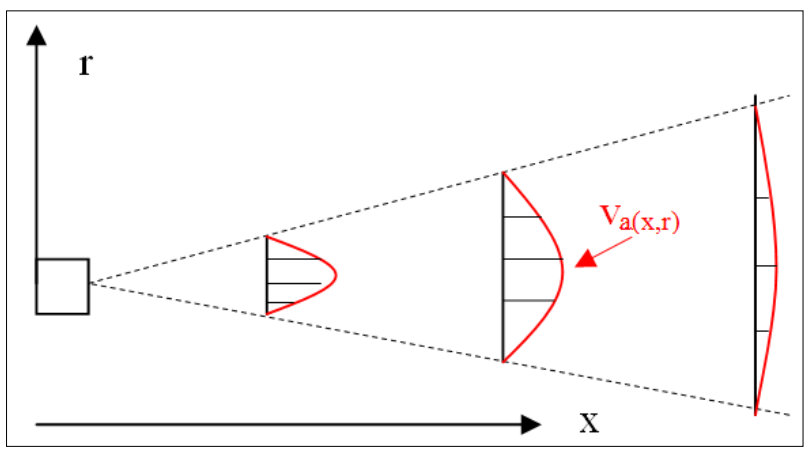

Fig. 9 Nozzle coordinate system

All of these ingredients were implemented in our in-house massively parallel code ESPRESO, which is a massively parallel framework based on the finite element method for engineering application. The free license for the developed package allows automatized simulation chains such as automatized systems for optimization to be created above the "solver as a service" platform. The added value of this package is a highly scalable solver based on the methods of domain decomposition. It allows the computational capacity of the state-of-the-art supercomputers to be fully utilized and solve problems with billions of unknowns. In addition, the advantage of this package is also its simple interface for configuration of the implemented solvers.

Figure 10 shows temperature comparison between CFD and FEM simulations at top wall of the aluminium profile. The Minimum temperature at the end of the profile was approximately $200^{\circ} \mathrm{C}$ for FEM analysis and $175^{\circ} \mathrm{C}$ for CFD analysis. The results are similar for other walls.

\section{CFD \& FEM Comparison}

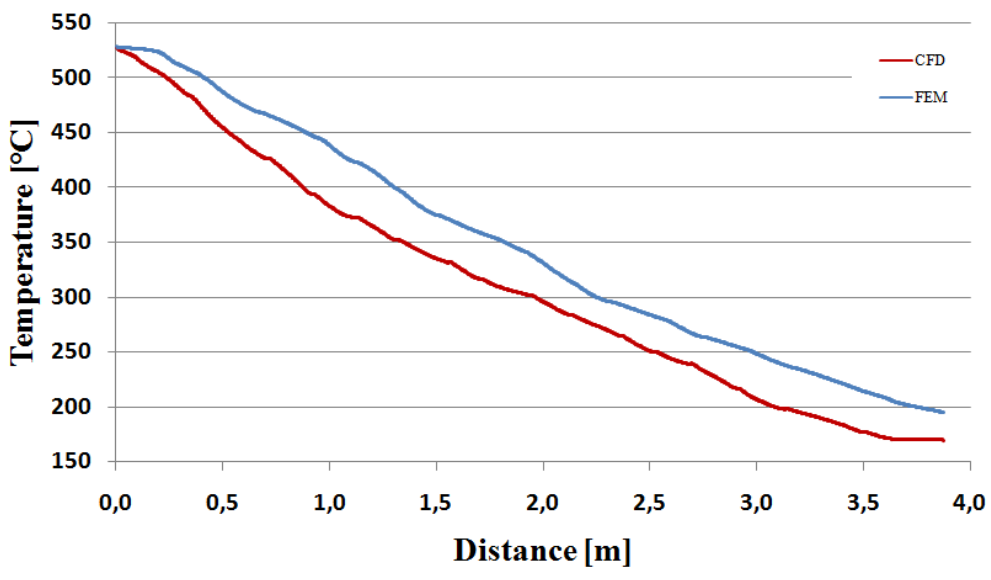

Fig. 10 Comparison of results obtained by CFD and FEM simulation

\section{CONCLUSION}

In the first phase, the velocity and temperature distribution near the aluminium profile surface were calculated by the CFD method. Due to the complexity of the computational CFD problem, many simulations were calculated with simplifying physical assumptions that occur while cooling aluminium profiles inside the WQ. The temperature distribution was compared with the measured values at the outlet of the water quench. Next stage the formula for calculating the heat transfer coefficient was applied as a boundary condition in to the FEM solver ESPRESO after obtaining the corresponding results. The reference formula was taken from the literature and was subsequently adapted to correspond to the results obtained by 
CFD analysis. The difference between FEM and CFD results is up to $10 \%$. Computing time has been reduced from days to hours.

One of the world's leading manufacturers of aluminium profile cooling equipment is Ferram Strojírna s.r.o. It has developed a revolutionary nozzle shape that accelerates the large volume of low pressure water - air mixture to achieve the desired heat dissipation effect from the profile surface.

The newly developed and by physical experiments verified methodology based on combination of CFD and FEM heat transfer simulations will be used by company Ferram Strojírna s.r.o to develop a new generation of nozzles in the future. The methodology will make it possible to cool down profiles that cannot be cooled today by existing equipment.

\section{ACKNOWLEDGEMENTS}

This work was supported by The Ministry of Education, Youth and Sports from the National Programme of Sustainability (NPS II) project "IT4Innovations excellence in science - LQ1602”.

\section{REFERENCES}

[1] Blejchař, T. "Návody do cvičení Modelování proudění-CFX", 1.vyd.Ostrava: VŠB-TU, 133 pp., 2009. ISBN 978-80-248-2050-7 Available at:http://www.338.vsb.cz/PDF/ Blejchar-CFX.pdf [Accessed: 12.3.2018]

[2] Blejchař, T.,"Turbulence Modelování proudění - CFX", učební texty. 1.vyd.Ostrava: VŠB-TU, 259 pp, 2010. Available at: http://www.338.vsb.cz/PDF/Turbulence_ESF_ v4.pdf [Accessed: 12.3.2018]

[3] Wright, P.,"Heat Transfer Coefficients for Two-Phase (Water/Air) Flow Over a Tube Bank", Master of Science, Air Force Institute of Technology, 1972.

[4] Hazman, S., Mokhtar, A., Ahmad, I. Md. I., Endri, R., Zainal, A. A. "Evaluation of Properties and FEM Model of the Friction Welded Mild Steel-Al6061-Alumina", Material Research 16 (2), 453 - 467, 2013. DOI: 10.1590/S1516-14392012005000178

[5] Turns, S.R., Kraige, R. D., "Property Tables for Thermal Fluids Engineering", Cambridge University Press, 230 pp., 2007. ISBN 978-0-521-70922-4 Available at: http://www.338.vsb.cz/wp-content/uploads/2016/03/Kozubkova-Fluent.pdf

[6] James, R. W., Charles, E. W., Robert, E. W., Gregory L. R. "Fundamentals of Momentum, Heat and Mass transfer", 5th edition, John Wiley and Sons. 327 pp., 2008.

[7] Rodi W., "In Studies in Convection", P. 79-165; Launder, B.E., Editor, Academic Press, London, 1975.

[8] Abramovich, G.N., "The Theory of Turbulent Jets", The MIT Press, 1963.

[9] Rajaratnam, N., "Turbulent Jets", Elsevier Scientific Publishing, 1976.

[10] Vishwanath, M., Lakshaman, A.N., Ramesh G.K. "Numerical Simulation of Heat Transfer Behaviour of Dissimilar AA5052-AA6061 Plates in Friction Stir Welding: An Experimental Validation", Strojnícky časopis - Journal of Mechanical Engineering 69 (1), pp. 131 - 142, 2019. DOI: 10.2478/scjme-2019-0011

[11] Mlkvik, M., Olšiak, R., Smolar, M. "Comparison of the Viscous Liquids Spraying by the OIG and the Oil Configurations of an Effervescent Atomizer at Low Inlet Pressures", Strojnícky časopis - Journal of Mechanical Engineering 66 (1), pp. 53 - 64, 2016. DOI: $10.1515 /$ scjme-2016-0011 